\title{
A evolução do estilo musical sertanejo nos dias atuais: do caipira ao universitário
}

Este trabalho aborda a evolução do sertanejo caipira até o novo estilo musical denominado sertanejo universitário. O propósito deste estudo é demonstrar como o estilo simples, recatado e do sertão, deu origem ao sertanejo universitário e comprovar a hipótese de que houve um crescimento muito grande desse gênero musical até os dias atuais. Para alcançar este objetivo, a pesquisa, de cunho bibliográfico e documental, utilizará artigos científicos, livros e dados do Escritório Central de Arrecadação (ECAD) entre os anos de 2013 a 2015. O ritmo caipira passou várias etapas durante seu crescimento e superou vários preconceitos para tocar nas emissoras de rádios e cair no gosto popular. A análise demonstrou que o ritmo sertanejo passou por diversas mudanças até chegar no ritmo dos dias atuais, e com isso, concluiu-se que várias dessas fases colaboraram para que esse crescimento do estilo fosse significativo em relação ao seu início caipira, destacando principalmente suas grandes realizações e participações em rádio, televisão, shows, e outras formas de arrecadação. Atualmente, o cenário musical está propício à criação e ao desenvolvimento econômico sustentável de empreendimentos musicais de pequeno e médio porte. O que antes era somente música, agora virou negócio. Um mercado competitivo e nem sempre justo no cenário fonográfico, pois quanto mais investimento correto e efetivo houver, mais êxito terá no negócio e possivelmente o cantor/banda irá conseguir se sobressair aos demais artistas que não estão no mesmo patamar de negócios ou financeiro.

Palavras-chave: Música Sertaneja; Evolução do Caipira; Sertanejo Universitário.

\section{The evolution of sertanejo music style in current days: from caipira to university}

\begin{abstract}
This work approaches the evolution of the backwoods back to the new musical style called the university sertanejo. The purpose of this study is to demonstrate how the simple style, modest and sertão, gave rise to the university sertanejo and prove the hypothesis that there was a great growth of this musical genre to the present day. To reach this objective, the bibliographical and documentary research will use scientific articles, books and data from the Central Collection Office (ECAD) between the years of 2013 to 2015 . The country rhythm has undergone several stages during its growth and overcame several prejudices to play radio stations and fall into popular tastes. The analysis showed that the sertanejo rhythm underwent several changes until arriving at the rhythm of the present days, and with that, it was concluded that several of these phases collaborated so that this growth of the style was significant in relation to its beginning Hickman, mainly highlighting its great achievements and participation in radio, television, shows, and other forms of collection. Today, the musical scene is conducive to the creation and sustainable economic development of small and medium-sized musical enterprises. What was once just music, now turned into business. A competitive and not always fair market in the phonographic scenario, because the more correct and effective investment there is, the more success you will have in the business and possibly the singer / band will be able to stand out to the other artists who are not at the same level of business or financial.
\end{abstract}

Keywords: Sertanejo Music; Evolution of the Caipira; Sertanejo University.

Topic: Música

Reviewed anonymously in the process of blind peer.
Received: $15 / 05 / 2019$

Approved: 22/09/2019
Luiz Otávio Silva Reis

Centro Universitário do Sul de Minas, Brasil

luizotaviocomex@hotmail.com

Sheldon William Silva (iD)

Instituto Federal do Norte de Minas Gerais, Brasil

http://lattes.cnpq.br/5691436224279198

http://orcid.org/0000-0002-2473-5728

sheldonwilliamsilva@gmail.com

Lucas Rosa Paiva (iD

Centro Universitário do Sul de Minas, Brasil

http://lattes.cnpq.br/7560579130730003

http://orcid.org/0000-0002-3252-9959

lucas@unis.edu.br

\section{Pedro dos Santos Portugal Júnior (iD \\ Centro Universitário do Sul de Minas, Brasi \\ http://lattes.cnpq.br/3402598684545658 \\ http://orcid.org/0000-0003-2590-1959 \\ pedrorotaract@hotmail.com \\ Fabricio Pelloso Piurcosky (iD \\ Centro Universitário do Sul de Minas, Brasil \\ http://lattes.cnpq.br/9736654155430529 \\ http://orcid.org/0000-0001-5458-5129 \\ fabricio@unis.edu.br}

\section{Referencing this:}

REIS, L. O. S.; SILVA, S. W.; PAIVA, L. R.; PORTUGAL JÚNIOR, P. S.; PIURCOSKY, F. P.. A evolução do estilo musical sertanejo nos dias atuais: do caipira ao universitário. Social Evolution, v.3, n.2, p.1-11 2019. DOI: http://doi.org/10.6008/CBPC2595-430X.2019.002.0001 


\section{INTRODUÇÃO}

O gênero musical sertanejo é brasileiro e se dá por uma variação ou urbanização da música caipira onde se originou os instrumentos como viola, acordeão e a gaita. O sertanejo atual é conhecido por suas melodias simples e melancólicas, chamado de um desenvolvimento das letras caipiras, até as letras da atualidade. A temática do sertanejo caipira era especialmente baseada sobre sua vida no campo, enquanto o sertanejo universitário mudou essa temática objetivamente para agradar seu público alvo, com temas de amor e traição (ANTUNES, 2012).

As modificações no escopo do gênero musical sertanejo, tem acarretado grandes discussões no país sobre o que seria a música caipira/sertaneja. Muitos estudiosos acreditam e seguem a tradicional tendência de integrar a música caipira e sertaneja como subgêneros dentro de um mesmo conjunto musical, que estabelece suas fases e divisões. De 1929 a 1944 é o período da música caipira (ou sertanejo raiz); da pósguerra até a década de 1960 como uma evolução da velha música raiz para o atual gênero sertanejo; e dos anos sessenta até a atualidade como música "sertaneja romântica" (ALONSO, 2011).

Por ter um certo conhecimento no ramo musical, vejo que é interessante toda essa transformação do estilo, do caipira para o universitário, e hoje em dia o quanto este novo ritmo engloba outros estilos. $O$ sertanejo Universitário nos dias atuais se baseia não somente à sua raiz, mas abre espaço para a entrada de outros estilos que talvez no momento atual não estejam tão sólidos, e assim serve como base um para o outro. Um estilo alavancando o outro. É notável que atualmente se utiliza um 'casamento de estilos' como por exemplo: samba junto com sertanejo, pagode, funk, música clássica, dentre outros estilos, casam-se uns com os outros, e tudo se transforma nessa mistura que já é o povo brasileiro. $O$ sertanejo atual atingiu todo esse patamar, porque antes de tudo se permitiu a mudança, e é conhecido por ser sempre o estilo que está em frequente crescimento. Essa mudança agrada não somente os jovens das baladas, das casas noturnas, mas também seguidores do estilo desde os tempos antigos, onde se predominava o sertanejo romântico, ou a raiz.

O objetivo deste estudo é buscar entender como o sertanejo universitário cresceu tanto desde as últimas décadas, e expor a história do caboclo (homem do campo) sertanejo desde os anos 1930 até os dias atuais, ressaltando o começo desta trajetória, e como chegou aos dias atuais mantendo um estilo totalmente diferente da sua origem, mas que traz os seus traços, e se adapta às mudanças do tempo e história. Esta tarefa será realizada através de pesquisa no Google Scholar, Youtube, Livros. Os artigos foram selecionados, de acordo com as buscas feitas através de palavras chaves como 'Sertanejo Universitário', 'Evolução do Caipira', 'Música Sertaneja'.

\section{REVISÃO TEÓRICA}

\section{A viola: surgimento e expansão}

A viola muito antes de desembarcar no Brasil já fazia parte da vida dos portugueses, tendo origem sua origem a princípio de instrumentos árabes como o alaúde. Naquele tempo, a viola servia para 
comemorações, e para animar as vidas dos grandes aventureiros que se distanciavam de seus familiares e encontravam na música uma morada (ANTUNES, 2012).

O caboclo e a viola andavam de mãos dadas, e na medida em que os colonos europeus se casavam com as índias, nasciam os primeiros mestiços da nova nação, chamados de caboclos, também conhecidos como "mamellucos", caiçara, "caribocas ou curibocas" (ANTUNES, 2012). A nacionalização da viola foi dada através dos caboclos que por sua mão de obra construíram cópias de instrumentos de Portugal dando assim um grande início a uma nova tradição que ajudaria a nova nação a mostrar seu talento musical.

Quem ajudou a expandir o hábito de tocar viola pelo interior do país fora os tropeiros. Nesta época a comunicação entre as vilas era muito pequena, quase não existia, e os tropeiros estabeleceram também um grande papel cultural, pois levavam notícias e ideias de um lugar para o outro juntamente com suas violas que na maioria das vezes estavam amarradas em um saco de linho, na garupa do seu animal. Segundo a obra de Melon (2013), na década de 1930 a 1950 a rádio presenciou e vivenciou sua chamada 'Era do Ouro' e se transformo no principal meio de divulgação de informações e artistas de vários gêneros.

Com toda essa história e crescimento se expandindo cada vez mais, e fez surgir uma elite paulistana, mas que continha valores europeus, e também valores franceses, e preconceituosamente desdenhava do homem simples que se habitava no campo. No interior não era muito diferente, a elite negava o caipira, tratando-o de forma inferior, como bobo e atrasado. Na era do rádio, sendo o primeiro meio de comunicação a falar individualmente com as pessoas, cada ouvinte era tocado de forma particular por mensagens que eram recebidas simultaneamente por milhares de pessoas. O novo meio de comunicação revolucionou a relação cotidiana do indivíduo com a notícia, imprimindo uma nova velocidade e significado aos acontecimentos (CALABRE, 2002).

Essa imagem ruim sobre o caipira foi desmitificada a partir da década de 1940, que foi quando Cornélio Pires que tinha um vasto conhecimento folclórico, realizou com grande sucesso e importância no colégio 'Mackenzie', um final de semana cultural em que o foco principal, eram as riquezas do universo caipira.

\section{A chegada do rádio: surgimento de oportunidades}

Antunes (2012) afirma após esta parte da história com a chegada da rádio, ajudou muito as pessoas a terem um olhar diferente sobre o caipira, ou seja, obtiveram um olhar mais maduro e cultural, que aos poucos foi se popularizando dentre a população. De forma semelhante na obra Transformação da Música Sertaneja do Século XX, Melon (2013) nos lembra que a chegada da rádio na década de 1920 foi muito importante para o crescimento e expansão do ritmo sertanejo. A sonoridade rural dos estados de São Paulo, Goiás, Mato Grosso do Sul, Paraná e Minas Gerais foi grandemente difundida e acabou se adaptando e pegando para si o termo 'sertanejo'. Porém, quando o autor supracitado fala da modernização da música brasileira, percebe-se suas adaptações para viabilizar as gravações. A chegada da música sertaneja nas gravadoras torna-se um marco, pois algumas canções como catiras, foram totalmente modificadas para ser gravadas. Em suma, o catira - subgênero da música sertaneja - que além da musicalidade, também detém 
uma contribuição cênica, seria restrito essa gravação, já que apenas seria possível a reprodução sonora.

A rádio a princípio era um instrumento de uso da elite e somente voltado para ela, pois só recebiam a programação quem tinha os receptores e pagava uma mensalidade para ouvir ópera, recitas de poesias e também palestras culturais (ANTUNES, 2012). Em 1936, os aparelhos de rádios que antes eram de difícil acesso, começaram a ser vendidos, e basicamente todos que na época tinham condições, poderia comprar o equipamento em lojas do ramo. Nos anos de 1960 os programas de rádio que faziam sucesso e fizeram nas décadas passadas, tinham se transferido na maior parte para a televisão. Foi a partir deste momento que aplicaram novos modelos de programação radiofônica, se distanciando cada vez mais dos modelos de antigamente nos "anos dourados" do rádio brasileiro (CALABRE, 2002).

\section{O estilo caipira agora se chama sertanejo}

Outro aspecto a ser abordado é que o surgimento da música sertaneja nos aparelhos radiofônicos e também nas gravadoras foi um grande passo para que o gênero iniciasse seu percurso por todo o brasil. Melon (2013) relata que Jararaca e Ratinho também fizeram parte desta história de geração. Alvarenga e Ranchinho, Caçula e Mariano e Cornélio Pires, foram os grandes incentivadores e divulgadores desta musicalidade na década. Com esse cenário houve uma facilidade para novas elaborações musicais não abrangendo somente o ritmo caipira, mas também outros estilos presentes nas regiões.

As guitarras elétricas foram as grandes responsáveis e incentivadoras pela mudança e transformação na música sertaneja. Influenciados pela música country norte-americana, a dupla Milionário e José Rico acrescentaram em suas canções um novo instrumento: a guitarra elétrica, instrumento que na década de sessenta estava no mainstream por bandas de rock. Então, o sociólogo José Roberto Zan escreve que: Uma nova modalidade de música sertaneja começa a ser produzida a partir de então. Novas duplas se destacam nesse período como Milionário e José Rico, Léo Canhoto e Robertinho, entre outros. O repertório produzido por essas duplas confunde-se com outro segmento, também em expansão chamado 'brega'. Eram canções com temáticas românticas e melodramáticas que anunciavam a produção que se destacou no mercado fonográfico brasileiro a partir dos anos 80 com as duplas Chitãozinho e Xororó, Zezé de Camargo e Luciano, Leandro e Leonardo, Gian e Giovani, dentre outras (ZAN, 2004).

Percebe-se que neste período alguns artistas eram responsáveis por reproduzirem um repertório que continham músicas de origem 'raiz' . No entanto, a dupla Milionário e José Rico tinha um segmento onde suas influências eram tiradas das origens norte-americanas, no que consequentemente levava a dupla por um caminho que estabelecia uma proposta um pouco diferente dos demais artistas da época que já vinham em um mesmo segmento. O sertanejo romântico. Esse estilo musical passou a ser identificado por críticos musicais e pesquisadores como 'sertanejo pop', 'sertanejo romântico' ou 'neo sertanejo', dirigido a um público suscetível à 'modernização' da música sertaneja. Após um grande trabalho de marketing, as duplas passaram a ser presença carimbada em todos os programas televisivos e na grande mídia. Mudou o estilo das vestimentas, incorporou o uso de instrumentos musicais eletrônicos, as composições e arranjos passaram a ter elementos da música urbana de massa, especialmente nas baladas românticas, mas também 
faz parte da estratégia colocar no repertório pelo menos uma música de "raiz" (ARAÚJO, 2010).

A indústria fonográfica brasileira se interessou profundamente por esse estilo, e investiu no segmento, onde obtiveram grande sucesso com as vendas de CD's dos artistas e com isso promovendo um grande consumo específico do estilo. Salazar (2010) ressalta que a música é a manifestação artística mais entranhada na sociedade, presente em todos os grupos sociais e em diferentes faixas etárias. Anderson (2006) demonstrou que o negócio da música é composto por milhares de nichos. Música para ninar, música para brincar, música para dançar, música para se apaixonar, música para protestar, música para relaxar. Do brega ao jazz, do axé à MPB, do pagode ao blues, do forró à música clássica, do sertanejo ao rock. Não há mais o grande mercado, o grande hit, a grande estrela da música, mas milhares de micromercados, de mini hits e de artistas satélites.

O período que corresponde aos anos 80 e 90 Foi marcado pelo advento de novas tecnologias na área Fonográfica que levaram ao barateamento do processo de produção. Os custos para a montagem de pequenos estúdios, em condições de realizar gravações de qualidade, tornaram-se mais acessíveis. Consequentemente, multiplicaram-se pequenas gravadoras (Indies), selos e artistas independentes. A indústria Fonográfica sofreu uma reestruturação. As grandes gravadoras (majors) passaram a terceirizar serviços, convertendo-se, geralmente, em escritórios executivos. Simultaneamente, reforçaram o controle sobre a divulgação e a distribuição de Fonogramas para garantirem o monopólio do mercado. Nesse contexto, as experiências com lançamentos de novos gêneros e novos artistas passam a ser feitas, em geral, por pequenas gravadoras e selos independentes. E uma grande gravadora somente demonstra interesse em contratar um artista quando este der demonstrações de que foi capaz de conquistar um determinado público e de que tem condições de expandi-lo. Pode-se dizer que, ao mesmo tempo em que controlam a divulgação e a distribuição, as grandes gravadoras terceirizam os riscos de investimentos em novidades (ZAN, 2001).

\section{A indústria fonográfica brasileira}

Neste mercado, o sonho de todo jovem cantor é conseguir obter sucesso trabalhando com música e adquirir renda com esse instrumento de trabalho. Infelizmente a minoria acaba conseguindo este êxito, pois além de dedicação, o músico tem que estudar e conseguir ver esse mercado de forma ampla, e promissora. $\mathrm{E}$, além disso, é de grande ajuda saber que neste campo, não somente de banda autoral se vive o músico. Há diversas possibilidades de negócio que poderiam beneficiar neste meio como, composições, produção independente de outros artistas, consultoria musical, dentre diversos outros segmentos. Possibilitando assim uma grande soma de todos os trabalhos trazendo uma renda significativa no final dos trabalhos.

No cenário atual de grande competitividade, as grandes corporações vêm investindo fortemente em estratégias de marketing/publicidade e em repertórios simbólicos específicos relacionados à sua marca. Ao mesmo tempo, podem apoiar produções culturais de determinada região e, com isso, melhorar a imagem perante a população daquele território. Nesse contexto, mais do que nunca a indústria cultural de uma determinada localidade é crucial para o desenvolvimento não apenas pelo que ela representa com setor produtivo em si, mas pelo que esta indústria pode agregar de valor ao restante da produção deste território 
(HERSCHMANN et al., 2006).

Atualmente a indústria demonstra sinais de razoável recuperação, mas isso se deve mais ao crescimento momentâneo do mercado de DVDs do que propriamente a um desenvolvimento do mercado tradicional ou mesmo online. 160 que não quer dizer que não seja possível que esteja na eminência da reorganização desta indústria e na consolidação de novos modelos de negócio que, por um lado, garantirão a reprodução do capital 17 e, por outro, podem abrir novas oportunidades para as PMEs, aliás, argumento defendido por vários autores que vêm investigando o mercado de música online atual. Entretanto, a Internet permanece uma arena imprevisível para a indústria, que, desde fins dos anos 90, busca fórmulas para lucrar na rede mundial de computadores. A grande indústria vem encontrando dificuldades em convencer um consumidor a pagar - seja mais de $\mathrm{R} \$ 30$ por um $C D$, seja um preço simbólico por um download legalizado - por algo que está disponível gratuitamente em diversos sites. "É difícil competir com algo que é grátis", admitiu em entrevista ao Wall Street Journal o diretor-presidente da EMI Recorded Music, Ken Berry 18.

No cenário atual existem diversas formas de se obter rendimentos com a músicas. Havia sido mencionado sobre alguns deles por aqui e quais os seus procedimentos na obtenção do lucro artístico. Escritório Central de Arrecadação e Distribuição mais conhecido por ECAD. Um escritório privado brasileiro responsável pela arrecadação e distribuição dos direitos autorais das músicas aos seus autores.

\section{METODOLOGIA}

Para entender como se deu o crescimento do atual ritmo sertanejo universitário, denominado anteriormente como caipira, se faz identificar como foi o crescimento deste ritmo, analisar sua história e buscar compreender qual a ligação do mundo atual com a época antiga. O que mudou de lá para cá, como mudou, suas consequências, suas originalidades musicais e culturais. A pesquisa qualitativa foca no caráter subjetivo do objeto analisado, estudando as suas particularidades e experiências individuais, por exemplo.

Ter o ambiente natural como sua fonte direta de dados e o pesquisador como eu principal instrumento. A pesquisa qualitativa supões o contato direto e prolongado do pesquisador com o ambiente e a situação que está sendo investigada, via de através do trabalho intensivo de campo. Por exemplo, se a questão que está sendo estudada é a da indisciplina escolar, o pesquisador procurará presenciar o maior número de situações em que está se manifeste, o que vai exigir um contato direto e constante com o dia-adia escolar.

A escolha da pesquisa qualitativa como metodologia de investigação é feita quando o objetivo do estudo é entender o porquê de certas coisas, como a escolha dos eleitores, a percepção dos consumidores, e etc. Como técnica de investigação, o estudo utiliza as pesquisas bibliográfica e a documental. A pesquisa bibliográfica é desenvolvida com base em material já elaborado, constituído principalmente de livros e artigos científicos. Embora em quase todos os estudos seja exigido algum tipo de trabalho dessa natureza, há pesquisas desenvolvidas exclusivamente a partir de fontes bibliográficas. Boa parte dos estudos exploratórios pode ser definida como pesquisas bibliográficas. As pesquisas sobre ideologias, bem como aquelas que se propõem à análise das diversas posições acerca de um problema, também costumam ser 
desenvolvidas quase exclusivamente mediante fontes bibliográficas (GIL, 2002).

Corroborando, Cervo et al. (1983) argumentam que "a pesquisa bibliográfica como a que explica um problema a partir de referenciais publicados em documentos". Pode ser realizada independentemente ou como parte da pesquisa descritiva ou experimental. Ambos os casos buscam conhecer e analisar as contribuições culturais ou científicas do passado existentes sobre um determinado assunto, tema ou problema. Tendo em uso também a pesquisa documental, destaca como principal diferença entre esses tipos de pesquisa a natureza das fontes de ambas as pesquisas e chega a ser confundida com a pesquisa bibliográfica. Ainda de acordo com o autor, a pesquisa bibliográfica utiliza-se principalmente das contribuições de vários autores sobre determinada temática de estudo. Já a pesquisa documental baseia-se em materiais que ainda não receberam um tratamento analítico ou que podem ser reelaborados de acordo com os objetivos de pesquisa (GIL, 2002).

Segundo Silva et al. (2009), a pesquisa documental, enquanto método de investigação da realidade social, não traz uma única concepção filosófica de pesquisa, pode ser utilizada tanto nas abordagens de natureza positivista como também naquelas de caráter compreensivo, com enfoque mais crítico. Essa característica toma corpo de acordo com o referencial teórico que nutre o pensamento do pesquisador, pois não só os documentos escolhidos, mas a análise deles deve responder às questões da pesquisa, exigindo do pesquisador uma capacidade reflexiva e criativa não só na forma como compreende o problema, mas nas relações que consegue estabelecer entre este e seu contexto, no modo como elabora suas conclusões e como as comunica.

Visando comprovar a hipótese de que houve um crescimento muito grande desse gênero musical até os dias atuais, a pesquisa utilizará os dados do Escritório Central de Arrecadação (ECAD) entre os anos de 2013 a 2015. De acordo com Brida (2012), a Lei 5.988 de 14 de dezembro de 1973 permitiu às associações dos titulares de direitos autorais que organizassem um escritório central de arrecadação e distribuição dos direitos relativos à execução pública das composições musicais, lítero-musicais e de fonogramas, surgindo então o ECAD. Privilegiaram-se os dados oriundos dos rankings anuais de músicas mais executadas e autores com maiores rendimentos entre os anos de 2013 e 2015

\section{RESULTADOS E DISCUSSÃO}

A música caipira passou por diversas etapas até chegar no cenário atual da indústria fonográfica, onde se tem diversas formas de ganhar dinheiro com o trabalho autoral e empreendedor. Estas etapas colaboraram fortemente para o crescimento do estilo, como por exemplo a chegada da rádio, que após certo tempo passou a autorizar comerciais em $10 \%$ da programação total que se tinha. Tendo que a partir deste momento as rádios começaram a buscar diversos artistas e produtores para adicioná-los em suas programações.

A partir dos anos de 1936, os aparelhos de rádios que antes eram de difícil acesso, começaram a ser vendidos, e todos que na época tinham condições, poderia comprar o equipamento em lojas do ramo. Outro grande passo para que o gênero se espalhasse por todo o brasil, foi o surgimento do sertanejo nos aparelhos 
radiofônicos e nas gravadoras. As guitarras elétricas também modificaram o mercado, dando um charme nas músicas e inovando completamente o estilo que antes usava instrumentos específicos como a viola.

Alguns cantores da época traziam uma diferença notável já percebida em suas letras musicais. Milionário e José Rico usavam a guitarra elétrica em seu repertório, e chegaram a confundir seu público com suas canções lembrando o estilo musical 'brega'. Eram canções com temáticas românticas e melodramáticas que buscavam a produção que se destacou no mercado fonográfico brasileiro a partir dos anos 80 com as duplas que inovaram o mercado como Chitãozinho e Xororó, Zezé de Camargo e Luciano, Leandro e Leonardo, Gean e Giovani, dentre outras (ZAN, 2004).

Com toda essa evolução, o sertanejo passou a ser chamado por críticos musicais e pesquisadores de 'sertanejo pop' ou 'neo sertanejo', dirigido a um público suscetível à 'modernização' da música sertaneja. A indústria fonográfica se interessou profundamente por esse estilo inovador e promissor e investiu no segmento, onde obtiveram grande sucesso com as vendas de CD's dos artistas e com isso promovendo um grande consumo específico do estilo.

Com base nos dados fornecidos pelo site do ECAD, sua distribuição dos direitos autorais de execução pública musical, tem como base critérios utilizados internacionalmente e definidos por sua Assembleia Geral, composta pelas associações de gestão coletiva musical. As associações são responsáveis pela fixação de preços e pela definição de todas as regras de arrecadação e distribuição dos valores.

Para fazer parte do sistema brasileiro de gestão coletiva musical, e ter seus direitos autorais protegidos, é preciso que o titular se filie a uma das sete associações que administram o ECAD. No ato de sua filiação, deve informar todo o seu repertório à associação escolhida, inclusive com os percentuais de participação em cada obra musical ou fonograma e parcerias, se houver. Uma vez filiado, a associação de música se torna mandatária para a prática de todos os atos necessários à defesa de seus direitos autorais, inclusive o de cobrança e distribuição dos valores decorrentes de execução pública musical. Sendo o ECAD organizado pelas associações para realizar a arrecadação e o processamento da distribuição, ele passa então a ser o representante de milhares de titulares filiados a estas associações.

Após o recebimento dos valores arrecadados, o ECAD realiza a captação e identificação das músicas executadas em cada segmento e, em seguida, efetua a distribuição desses valores. Dos valores arrecadados pelo ECAD, $85 \%$ são repassados para os titulares filiados às sociedades de gestão coletiva musical. Outros $5 \%$ são destinados às associações, para cobrir suas despesas operacionais, enquanto os $10 \%$ restantes são destinados ao ECAD para pagamento de suas despesas administrativas em todo o Brasil.

Os grandes cantores e compositores do Sertanejo, e de todos os outros estilos, conseguem através deste escritório a remuneração por sua obra realizada. Através disto, qualquer lugar onde haja rádio, onde haja uma música sendo executada, eles conseguem ter o controle dos direitos da música ouvida, e consequentemente total administração sobre os arrecadamentos e os repasses desses trabalhos. Fazendo um parâmetro sobre as arrecadações do ramo musical, destacando o ritmo Sertanejo Universitário nos dias atuais, pude analisar que os artistas que mais arrecadam anualmente, no segmento de autores com maiores rendimentos em 2017, colocando em uma escala de 1 a 5 foram: Marília Mendonça 1ㅇ; Eduardo Costa 3o; 
Paula Fernandes 60; Sorocaba (Fernando e Sorocaba) 9; Matheus (Matheus e Kauan) 16․

Por outro olhar, agora mais expressivo e objetivo em relação à pesquisa, foram recolhidos dados de rankings das músicas mais executadas no período dos anos 2013/2017, e pude perceber que na maior parte dos anos, a música sertaneja atual predominou o ranking com suas canções de sucesso mais executadas ficando nas primeiras posições, conforme Quadro 1.

Quadro 1: Músicas mais executadas entre os anos 2013/2017.

\begin{tabular}{|c|c|c|c|c|}
\hline 2013 & 2014 & 2015 & 2016 & 2017 \\
\hline $\begin{array}{l}\text { 70 Vidro fumê - Carlos } \\
\text { Colla/Kaliman } \\
\text { Chiappini }\end{array}$ & $\begin{array}{l}\text { 10 Fui fiel - Fábio } \\
\text { O'Brian/Pablo/Magno } \\
\text { Santana/Filipe Escandurras }\end{array}$ & $\begin{array}{l}\text { 20 Maus bocados - } \\
\text { Gerson } \\
\text { Gabriel/Rafael/Bruno } \\
\text { Varajão }\end{array}$ & $\begin{array}{l}\text { 10 escreve aí - Dudu } \\
\text { Borges/Bruno } \\
\text { Caliman/Luan } \\
\text { Santana/Douglas Cezar }\end{array}$ & $\begin{array}{l}\text { 10 Medo bobo -Vinícius } \\
\text { Poeta/Junior Pepato/Juliano } \\
\text { Tchula/Maraísa/Benício Neto }\end{array}$ \\
\hline $\begin{array}{l}\text { 9o Gatinha assanhada - } \\
\text { Gabriel Valim/Alex } \\
\text { Ferrari }\end{array}$ & $\begin{array}{l}\text { 20 Maus bocados - Gerson } \\
\text { Gabriel/Rafael/Bruno } \\
\text { Varajão }\end{array}$ & $\begin{array}{l}\text { 3o Jeito Carinhoso - Allê } \\
\text { Barbosa }\end{array}$ & $\begin{array}{l}\text { 2o Sapequinha - Ivan } \\
\text { Medeiros/Eduardo } \\
\text { Costa/Cabrera }\end{array}$ & $\begin{array}{l}\text { 2 Bom - Umberto } \\
\text { Tavares/Jefferson Junior }\end{array}$ \\
\hline $\begin{array}{l}\text { 10 Louquinha - Dennis } \\
\text { Dj }\end{array}$ & $\begin{array}{l}\text { 3o Domingo de manhã - } \\
\text { Bruno Caliman }\end{array}$ & $\begin{array}{l}\text { 4ㅇ Domingo de manhã - } \\
\text { Bruno Caliman }\end{array}$ & $\begin{array}{l}\text { 4o Bem feito - Renan } \\
\text { Gouveia }\end{array}$ & $\begin{array}{l}\text { 40 } 50 \text { reais - Waleria } \\
\text { Leão/Alex/Maykow } \\
\text { Melo/Naiara Azevedo/Bruno } \\
\text { Mandioca }\end{array}$ \\
\hline $\begin{array}{l}\text { 110 te esperando - } \\
\text { Bruno Caliman }\end{array}$ & $\begin{array}{l}\text { 40 Lepo lepo - Magno } \\
\text { Santana/Filipe Escandurras }\end{array}$ & $\begin{array}{l}\text { 60 Gordinho gostoso - Dj } \\
\text { Ivis }\end{array}$ & $\begin{array}{l}\text { 5o Isso cê num conta - } \\
\text { Caco Nogueira/Thiago } \\
\text { Teg/Douglas Cezar }\end{array}$ & $\begin{array}{l}\text { 5o eu, você, o mar e ela - } \\
\text { Dudu Borges/Luan } \\
\text { Santana/Douglas Cezar }\end{array}$ \\
\hline $\begin{array}{l}\text { 12 Camaro amarelo - } \\
\text { Marcia Araújo/Marco } \\
\text { Aurélio/Thiago } \\
\text { Machado/Bruno } \\
\text { Caliman }\end{array}$ & $\begin{array}{l}\text { 5 Parabéns a você - Lea } \\
\text { Magalhães/Mildred Junius } \\
\text { Welch Hill/Patty Smith Hill }\end{array}$ & $\begin{array}{l}\text { 70 até você voltar - } \\
\text { Juliano Tchula/Marília } \\
\text { Mendonça }\end{array}$ & $\begin{array}{l}\text { 60 } 10 \text { Minutos longe de } \\
\text { você - Leo/Marcelo }\end{array}$ & 6ㅇ Infiel - Marília Mendonça \\
\hline $\begin{array}{l}\text { 13 Sogrão Caprichou - } \\
\text { Marcia Araújo/Bruno } \\
\text { Caliman/Luan } \\
\text { Santana/Cristiano } \\
\text { Savatti }\end{array}$ & $\begin{array}{l}\text { 60 Jeito carinhoso - Allê } \\
\text { Barbosa }\end{array}$ & $\begin{array}{l}\text { 8o não tô valendo nada - } \\
\text { Henrique Tavares/Juliano }\end{array}$ & $\begin{array}{l}\text { 70 Mudando de assunto } \\
\text { - Marcelo Melo/Theo } \\
\text { Jose/Ivan } \\
\text { Medeiros/Ane Abreu }\end{array}$ & $\begin{array}{l}\text { 9o pensa, explica - Elcio Di } \\
\text { Carvalho/Ruan Soares/Junior } \\
\text { Pepato/Michel Alves/Larissa } \\
\text { Ferreira }\end{array}$ \\
\hline $\begin{array}{l}\text { 140 Flor - Zé } \\
\text { Henrique/Renato } \\
\text { Barros }\end{array}$ & $\begin{array}{l}\text { 70 logo eu - Samuel } \\
\text { Deolli/Filipe Labret }\end{array}$ & $\begin{array}{l}\text { 9o logo eu - Samuel } \\
\text { Deolli/Filipe Labret }\end{array}$ & $\begin{array}{l}\text { 8o Aquele } 1 \% \text { - Vinicius, } \\
\text { o Poeta/Benício Neto }\end{array}$ & $\begin{array}{l}10 \text { o pronto falei - Eduardo } \\
\text { Costa }\end{array}$ \\
\hline
\end{tabular}

Estes comparativos servem para entender e observar o quanto o Sertanejo Universitário se tornou forte e predominante no cenário da música. Independente das suas raízes, o ritmo simples e recatado cresceu e tomou forma expressiva no mercado fonográfico brasileiro. Atualmente, com uma proposta um pouco diferente, mas ainda trazendo o que nunca foi tirando com as suas atualizações. A essência da música, suas verdades da vida em melodia, o jeito simples de cantar, e as letras simples e marcantes conquistaram o público brasileiro em geral e veio a se tornar um dos ritmos mais fortes do país. Todos estes artistas são consagrados por suas composições, e realização de trabalho com shows e eventos, o que os torna mais flexíveis e abertos a outros gêneros musicais. Neste caso a abertura seria para gravações, parcerias, e investimentos em outro segmento artístico. O que destaca o grande nível de empreendedorismo no ramo da música.

Ao refletir sobre o começo do segmento sertanejo, a gama que ele atingiu, e o que ele representa atualmente no cenário musical, é visível o quanto se expandiu e a proporção que ele tomou comparado a sua história inicial. O caboclo evoluiu, e com isso suas histórias e canções também ganharam letras e melodias diferentes. O grande marco de toda essa mudança histórica e cultural, foi que pelo estilo do sertão ter se originado do homem do campo, da roça, da poeira vermelha, ele não se desfez totalmente com o tempo. Através das canções mais atuais, e dos shows que são realizados, os artistas relembram em seus repertórios 
as músicas que mais marcaram as vidas das pessoas. Isto nos retrata o quanto o começo de toda essa história ainda está viva mesmo após todas as suas mudanças nesse espaço de tempo. O sertanejo é um ritmo simples, que expõe canções melódicas que são capazes de trazer emoções à todas as pessoas que as ouvem.

\section{CONCLUSÕES}

Retomando a pergunta inicial, o principal objetivo era identificar o crescimento do estilo musical sertanejo a partir das evoluções ocorridas, tomando por base os dados oriundos do ECAD entre os anos de 2013 a 2016. Tendo em vista que a música sertaneja tem toda uma história cultural e significativa para a pesquisa, foi abordado também como se deu o seu início da música e as principais mudanças que ocorreram até os dias atuais. Demonstra-se que o sertanejo caipira teve suas origens do caboclo homem do campo, que por sua própria mão de obra construíram cópias de instrumentos de Portugal dando assim um grande início a uma nova tradição que ajudaria a nova nação a mostrar seu simples talento musical e mudando toda a história do homem rural, o sertanejo.

Contudo, essa história e crescimento se engrandeceu cada vez mais, e fez surgir uma elite paulista, mas que obtinha alguns valores europeus, e também valores franceses, e preconceituosamente desdenhava do homem simples que se habitava no campo. A elite desdenhava do homem simples do campo, mas isso não chegou a durar muito. Cornélio Pires que tinha grande conhecimento folclórico, foi um grande contribuinte para a desmitificação dessa imagem do homem do campo, pois realizava eventos onde o foco principal era mostrar as riquezas do universo caipira. O rádio era a grande novidade, surpreendeu a todos, era o primeiro meio de comunicação a falar com as pessoas, cada ouvinte era tocado de forma particular por mensagens que eram recebidas por milhares de pessoas. Esse novo meio de comunicação revolucionou a relação do indivíduo com a notícia, transparecendo uma nova era de tecnologia e interação.

Durante muito tempo o rádio se tornou o principal meio de divulgação, mesmo na era televisiva se destacava pelos incontáveis ouvintes, apaixonados por rádio. Com isso, trouxe diversos benefícios para os cantores que buscavam se apresentar e divulgar seus trabalhos nas rádios. Esses trabalhos são feitos até os dias de hoje. Cantores se espalham pelo brasil para divulgarem suas músicas na busca do sucesso pelos ouvintes. Através das atualizações no cenário, a indústria também se solidificou e mudou com o passar dos anos. O ECAD (Escritório Central de Arrecadação e Distribuição), faz o trabalho de recolhimento dos direitos autorais e faz os repasses para todos os artistas filiados do brasil todo.

Diante desse cenário, percebe-se que o passar dos anos fez com que o povo brasileiro acolhesse o homem do campo sertanejo, e contribuiu para toda sua evolução histórica na música sertaneja. Atualmente pode-se dizer que o sertanejo universitário está transformado devido as suas alterações com o passar dos anos. Mas essas mudanças ajudaram e colaboraram com a cultura brasileira empregando diversas pessoas que vivem de música, que são donos do próprio negócio, que são empreendedores. E não se aplica somente a quem canta o estilo sertanejo para ser mais especifico. Essa janela se abriu para todos os outros estilos e fez mudar todo o cenário musical e fonográfico positivamente.

Este artigo demanda um maior aprofundamento sobre o tema abordado. Como limitações, destaca- 
se a baixa produção científica envolvendo essa temática, o que acabou por dificultar e empobrecer a discussão teórica e obtenção de dados para a análise dos resultados. Merece destaque o fato de o site do ECAD estar desatualizado e possuir um layout de página pouco amigável. Contudo, ainda se pode obter resultados suficientes para compreender a história e o crescimento elevado do ritmo sertanejo universitário nos dias atuais.

\section{REFERÊNCIAS}

ARAÚJO, R. B.. As relações de gênero no universo da música sertaneja goiana. 2010.

ANTUNES, E.. De caipira a universitário. São Paulo: Matrix, 2012.

ALONSO, G.. Cowboys do asfalto: Música sertaneja e modernização brasileira. 2011.

BRIDA, A. C.. As limitações do ECAD-Escritório Central de Arrecadação e Distribuição-perante a Lei 9.610 de 1998 , quando atuante na fiscalização e arrecadação dos direitos autorais, com especial enfoque no poder de polícia administrativa. Monografia (Bacharel no Curso de Direito) Universidade do Extremo Sul Catarinense, Criciúma, 2012.

CALABRE, L.. A era do rádio. Zahar, 2002.

CERVO, A.; BERVIAN, P. A.. Metodologia científica. Cidade do México, 1990

GIL, A. C.. Como elaborar projeto de pesquisa. São Paulo: Atlas, 2002
HERSCHMANN, M.; KISCHINHEVSKY, M.. A indústria da música brasileira hoje: riscos e oportunidades.

In: Comunicação \& Música Popular Massiva. Salvador: EDUFBA, 2006. p.87-110.

MELON, C. A.. Transformação da música sertaneja do século XX: o jogo da contenção e absorção. 2013.

SALAZAR, Leonardo; ASSUNÇÃO, Luiz Márcio. Música, LTDA: o negócio da música para empreendedores. Recife: Sebrae, 2010.

SILVA, L. R. C.; DAMACENO, A. D.; MARTINS, M. C. R.; SOBRAL, K. M.; FARIAS, I. M. S.. Pesquisa documental: alternativa investigativa na formação docente. In: CONGRESSO NACIONAL DE EDUCAÇÃO, 9; ENCONTRO SUL BRASILEIRO DE PSICOPEDAGOGIA, 3. Anais. 2009. p.4554-4566.

ZAN, J. R.. Novos hibridismos na música sertaneja. In: MÚSICA POPULAR NA AMÉRICA LATINA, 5. Anais. 2004.

ZAN, J. R.. Música popular brasileira, indústria cultural e identidade. Eccos, v.3, n.1, p.105-122, 2001.

A CBPC - Companhia Brasileira de Produção Científica (CNPJ: 11.221.422/0001-03) detém os direitos materiais desta publicação. Os direitos referem-se à publicação do trabalho em qualquer parte do mundo, incluindo os direitos às renovações, expansões e disseminações da contribuição, bem como outros direitos subsidiários. Todos os trabalhos publicados eletronicamente poderão posteriormente ser publicados em coletâneas impressas sob coordenação da Sustenere Publishing, da Companhia Brasileira de Produção Científica e seus parceiros autorizados. Os (as) autores (as) preservam os direitos autorais, mas não têm permissão para a publicação da contribuição em outro meio, impresso ou digital, em português ou em tradução. 